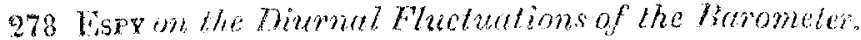

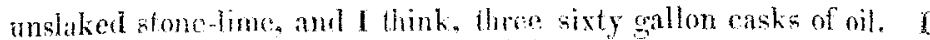
an not certain on this point, althongh I cannot ere greatly the con. sistence which the mixture must have, will be a snficient guide for the proportions. In the process of making, and applyiug it, the information which bave given is perfectly correct After it is prepared for use, it is kept in covered vessels to preserve it from the ram, or other moisture. 'The ship's bottom is prepared for sheathing in the usual way, by being paid with a coat of good half stufi, and allowed to cool, before the plaster is put on, as this accelerates its adhesion to the main bottom.

Althounh it is out of my province, and I am therefore unable, to form a jurgenent on this point, I have thought it worth inquiry whether this cheap coment might not be substituted for the costly $R$ oman, or Butch water coments. It would be worth the trial, whether it would not harden in fresh, as well as in salt vater, and answer the purpose of building piers, locks, and other structures under water.

If you think these remarks likely to be useful, please to insert them, and oblige,

Yours, \&c.

James Marsh,

On the cause of the Diunal Fluctuations of the Barometer.

TO TIT EDITOR OW THE FRANKLIN JOURNAT.

SIR,-Some years ago I communicated to the American Philosnphical society, a paper explanatory of the diurnal fluctuations of the Barometer. As that papet las not appeared in their transactions, and as no satistactory explanation of this phenomenon has appeared elsewhere, although it has been attempted by Professor Leslie and others, I send you the substance of it now for publication.

The phenonena, as observed by many philosophers, in the Wast and West Indies, and in various parts of the torrid zone, are the lollowing:-

From 6 to 10 in the morning, the barometer rises,

From 10 to 6 in the afternoon, it falls,

From 6 to 10 in the evening, it rises,

And from 10 to 6 in the morning, it falls.

Many ycars ago, Dr. Balfour instituted, at Calcuta, a most labo rious course of observations on this subject, in which the height ot the barometer was noted almost every half hour, for one lumation; and the preceding phenomena were observed, with but two or thee sligh exceptions. Humboldt observed nearly the same phenomena in the West Indies.

The cause of this fluctuation is so plain, that it is strange it did not occur to either of those philosophers. But it is still more stmine that $\mathrm{Mr}^{2}$. Ceslic, who has done so much for metcorology, should hate assigned so inarlequate a cause as the sea breene for this phenomenon. 
Nor has Mr. Daniell been successful in his attempt to elucidate these fluctuations by his laborious theory of the polar winds.

The true cause of this phenomenon is the expansion, and, of course, rise of the atmosphere by luat, and the contraction and consequent fall of the atmosphere by cold. Snppose just before sun-rise in the torrid zone, the temperiture of the air neither increasing nor diminishing, and of course the ar neither expating nor contracting, the barometer stands at 30 inches; now when the sun rises at 60 clock the air will begin to be heated near the surface of the earth, and of course, by its expanding, will elevate the superincumbent atmosphere; and this, by its inertia, will re-act on the an behow, and thus press harder on the mercury of the barometer, than if it were at rest-and the more rapidly it is forced upwards, the greater will be its re-action downwards, and of conse the more will the barometer be aftected. It is manifest that the most rapid increase of heat and rarefaction of the air will take place somewhere between sun-rise and three o clock, when the heat is the groatest, and this will evidently be near ten ochock, at which time he barometer will stand highest. Though the heat is still increasing, and of course the air expmuling yet the rapidity of increase alter this hour is not so great, and therefore the barometer will begin to lall, and at the moment of greatest heat, when the air is neither expanding nor contracting, the mercury will again stand 30 inches high. Jint now the air begins to contract from cold, and the mercury will thereiore continue to descend, and the rapidity of the descent will be in proportion to the rapidity of the contraction from cold. Perhaps this effect may be more clearly understood by imagrining an extreme case. Suppose the lower strata of atmosphere suddenly anmihilated, the mercury of the barometer would be relieved from all pressure for a moment, and fall down into the basin; and if annihilation removes all pressure from the mercury, a contraction of the lower strata by cold will remove some pressure, therefore the mercury will fall-at the moment therefore of a most rapid decrease of heat, wheh is probably near sunset; the mercury will stand lowest, and will be below the height of 30 inches, at which $l$ have supposed it to stand when the air is neither expanding nor contracting. 'The mercury will now begin to rise, for the rapidity of contraction diminishes from this moment, and the upper parts of the air are permitted more and more to press upon the lower with their whole weight, and even when the contraction ceases below, the upper parts having acquired a velocity downwarels, are inclined to continue that motion, and thus by their momentum will press upon the lower parts with a force greater than their natural gravity, and thas the barometer will rise above 30 inches, at which height it was supposed to stand when the air was neither contracting nor expanding. This effect must take place sometime in the night, and it seems probable. a priori, that it would be about ten or twelve o'clock. Now, as ific mercury at this hour stands higher than it does by the natural weint

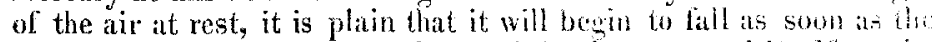
force of the superior parts of the air begins to spend itsell on the inferior, and when all motion downwards las ceased, the morcul 
will anain be pressed by the natuml weight of the atmosphere, and so stand at 30 inches. In this situation the sun will rise upon it, and the same fluctuations will be renewer.

\section{Lhiladelphiet, Murch 1st, 1827.}

J. P. Espr, Prol, Lan.

Postscript. - Since writing the above, I have seen the remaks of a very able witer in the $\Lambda$ merican Quarterly Review, on Mr. Daniell's theory: as the reviewer secms to think Mr. Daniell's theory satisfactory, I will merely add that it is not true, that " the lirst elfect of an increase of heat in the atmosphere will be to climinish its pres. sure," (see page 8 of last American (Quarterly Review;) but, on the contrary, the first effect of heat will be to increase the pressure, ant cause the air to move outwards and upwards, from where it is heated, and the current will not begin to run towarls the heated part until the whole column of air, over this part, becomes lighter by some of the superior parts rolling off from their greater clevation.

On the construction of a Kite, for cffecting a conmunication betwen a stranded Sheip and the Shore, or under olher circumestances, where badness of weather renders the ordinany means ingracticable. By Captarn Dansey.

A sA11, of light canvass or holland, is cut to the shape and adipted for the application of the principles of the common flying kite, and is launched from the vessel or other point, to windwand of the space over which a communication is reyuired, and as soon as it appears to be at a suflicient distance, a very simple and eflicacious mechancal apparatus is used to destroy its poise, and cause its immediate de. scent; the kite renaining, however, still attached to the line, and moored by a small anchor, with which it is equipped.

Whe kite, dung its flight, is attached to the line by two cords, pliacel in the ustal namer, which preserves its poise in the air; and to cause its descent, a messenger is employed, made of wood, with a small sail rigged to it. The line being passed through the cylin. dical hole of this messenger, the wind takes it rapidly up to the kite, where, striking against a part of the apparatus, it releases the upper cord, and by that means, the head of the kite becomes reversed. and it descends with rapidity.

In the experiments mate by Captain Dansey, with a view of yain. ing commanication with a lee-shore, under the supposition of no atssistance being there at land, a grapnel, consisting of four spetar shaped iron spikes, was fixed to the head of the kite, so as to moor it in its fall; and in this encrgency, the attempt of some person toget on shore illong the line, would be the neans resorted to. In those cases where a counumication has been ganed, and the mantainance of a correspondence bas been the object, the person to wind want hes attached a weight to the messenger, in some cises as unch as three 